\title{
10 \\ Clothing Industry 2000: The Archetype of the Extended Enterprise
}

\author{
I.P. Tatsiopoulos, I.A. Pappás, S. Ponis \\ National Technical University of Athens, \\ 15780 Zográfos, Athens, Greece \\ Tel.+3017723572, Fax. +3017723571 \\ E-Mail: itat@central.ntua.gr
}

\begin{abstract}
This is an account of work done in the CILC (Clothing Industry's Logistics and Communications) research project. A reference model is presented for logistics planning and production control in the clothing industry, organised as an extended enterprise. The CILC reference model is described according to the GIM (GRAI Integrated Methodology) formalism. Based on the above reference model, the first goal within the CILC project is to design and implement two system components in the industrial pilot Helen's Club SA, that is the hub of a network that forms an extended enterprise. The first component is the Logistics Planning Module (LPM) that provides support to multi-site and multi-firm production logistics. The second component, the Factory Scheduling Module (FSM), is designed for factories that belong to an extended enterprise network and supports their local production management needs.
\end{abstract}

Keywords

Clothing, extended enterprise, reference models

\section{INTRODUCTION}

The problem of the extended enterprise is how can a whole business system be organized so that it has (most of) the advantages of vertical integration and the advantages of subcontracting, without (most of) its drawbacks. The clothing industry 
is the archetype of the extended enterprise, many years in advance of the emergence of the term in the international litterature (Browne, Sackett and Wortmann, 1996). The Benetton story (Jarillo, 1993) is a well-referenced example of success that can be attributed to the extended-enterprise organisation concept. Benetton as well as many other clothing industries is a vertically de-integrated company, not only in manufacturing, but also in the other activeties that make up the business system: styling and design, manufacturing, logistics and distribution, and sales. They rely on external people and companies for the major part of these crucial activities. The specific production characteristics of the clothing indutry are:

1. Clothing is a labor-intensive industry, which means the existence of a dually constrained capacity environment (machines and labor skills).

2. There is considerable flexibility for capacity reallocation (of both people and machines).

3. The very nature of the basic raw material (fabric) plays a significant role. The formation and tracking of transfer lots (bundles) is due to the fact that the raw material is sensitive with respect to its exact coloring. The pieces cut off a particular bale of fabric must stay together in all the following production stages, in order to assure the homogeneity of coloring.

4. The proliferation of variants because various patterns are associated with different colors and sizes combined to the end products. This results in a multi-stage separation of customer orders, production orders, shop orders, and production lots (bundles), which increases the complexity of data and decision-making with respect to order release.

5. Production is usually organized in sequenced work groups whose internal organization may have a functional, group technology, or mixed character.

This is an account of research started with a BRITE research project (BRITE 1992) and continued with two more research projects, a finished project on Telematics and EDI (ICI, 1994) and a running project (CILC = Clothing Industry's Logistics and Communications) on Extended Enterprises (Helen's Club, 1996).

\section{OBJECTIVES AND METHODOLOGY}

This paper will present a reference model for logistics planning and production control in the clothing industry, organised as an extended enterprise. The CILC reference model will be described according to the GIM (GRAI Integrated Methodology) formalism, including:

1. A reference functional model using IDEF-0 diagrams

2. A reference physical model using IDEF-0 or Process Charts.

3. A reference data model using entity-relationship diagrams

4. A reference decision model using GRAI grids and GRAI nets. 
Based on the above reference model, the first goal within the CILC project is to design and implement two system components as prototypes and carry out tests in the industrial user, Helen's Club SA which is a clothing extended enterprise. The first component is the Logistics Planning Module (LPM) to support multi-site and multifirm production logistics. The second component, the Factory Scheduling Module (FSM), is designed for small and medium enterprises that belong to the extended enterprise network and supports their local production management needs.

The final long-term goal of the CILC project for the clothing industry is to link five innovative concepts:

1. Multi-site and multi-firm computerized production and logistics planning

2. Factory production control depending on multi-sourcing logistics strategies

3. Multi-site key indicators management and graphical monitoring

4. Decision support for multi-site logistics

5. Integrated application of Electronic Data Interchange (EDI).

\section{HELEN'S CLUB PRODUCTION PROCESS}

Helen's Club S.A was founded in 1976. Since then and for twenty years the company is growing continuously to be one of the ten most successful knitwear companies in Greece.

The key to this success is undoubtedly the company's strategy. Continuous change along with constant adaptation to market needs, close contact with customers, quick response to change, and an unrelenting effort to balance between being industrial and fashionable at the same time are some of the prerequisites that Helen's Club had to meet up with in order to succeed in the domestic and international market. Helen's Club could not have done otherwise than being an extended enterprise in most of the activities that make up the business system: styling and design, manufacturing, logistics, distribution and sales. In particular:

\section{Styling and Design}

Styling and design is a an entirely in-house activity. A small percentage (up to $20 \%$ ) of each season's collection is purchased as ready-to-wear clothing, usually from FarEast, French, and Dutch vendors. These clothes come unlabelled and are embodied in the original Helen's Club collection under the brand name 'Miss Raxevsky'.

\section{Logistics and Distribution}

Logistics and distribution for the Greek market are carried out mainly by the company's lorry fleet while a small part (reorder and flash order deliveries) is performed by national or other courier services.

\section{Sales}

Sales is performed by a retailing system of 25 "Miss Raxevsky" shops and three stockhouses, all over Greece. Twelve of those are owned by the company, while the 
other sixteen are franchised. In addition, there is a force of around eighty shops throughout the country that are licensed to sell "Miss Raxevsky" products.

\section{Manufacturing}

More than $80 \%$ of manufacturing is done outside the company by a force of approximately 50 subcontractors in Greece, four subcontractors abroad, and a jointventure company in Bulgaria. Figure 1 depicts the company's production process.

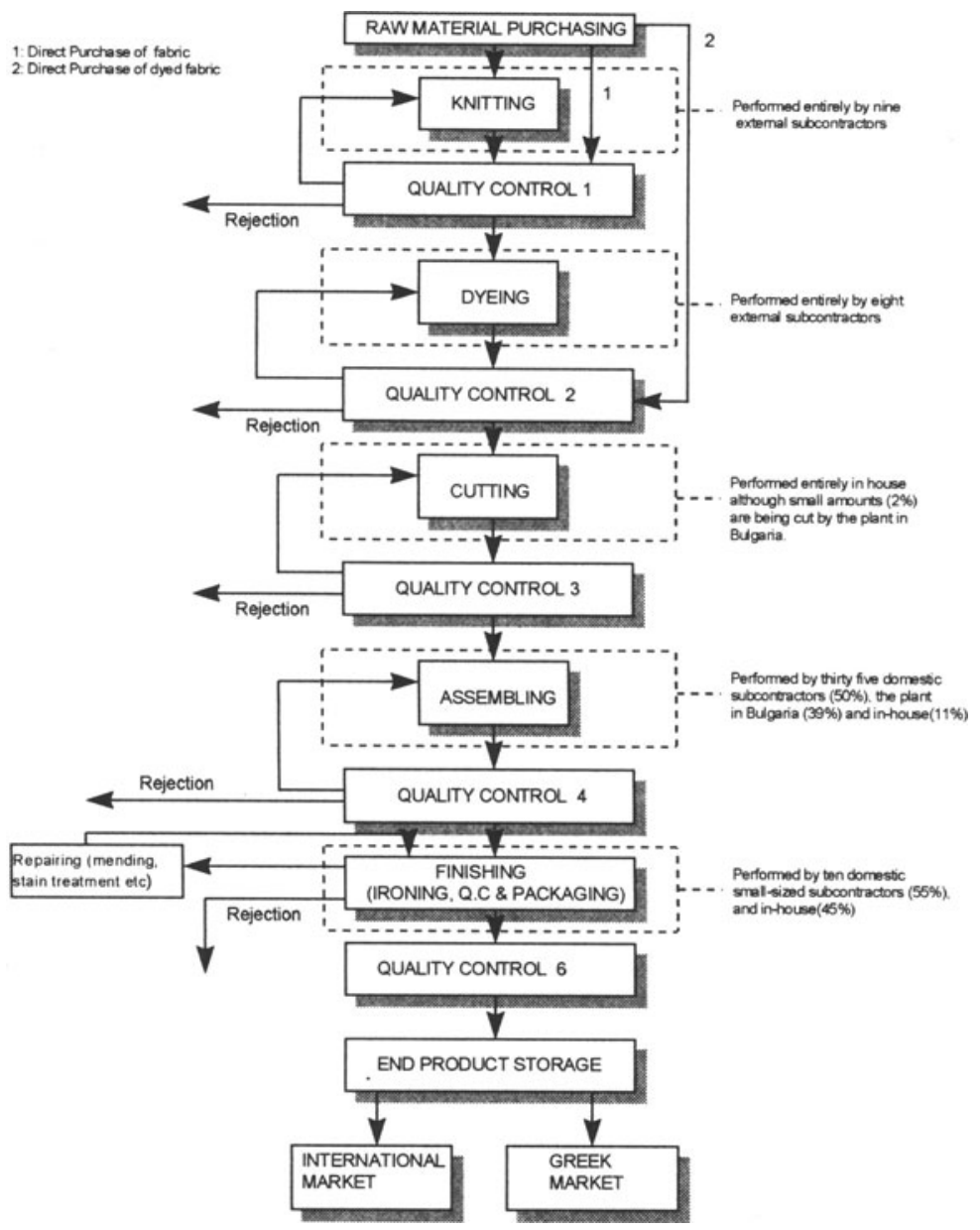

Figure 1 Physical model of Helen's Club extended enterprise.

Raw Material Purchasing

Raw materials in the clothing industry are yarn, (raw) fabric, and dyed/chemically treated fabric. The production phase to be activated is determined by the raw 
material purchased (e.g. buying fabric activates dyeing first while buying dyed fabric activates the cutting phase).

\section{Knitting}

In this phase, Helen's Club works with nine subcontractors, who carry out this production activity. As soon as the knitted yarn returns to the company's warehouse as fabric, a quality control takes place which determines the identity between the quality delivered and the quality agreed.

\section{Dyeing}

The approved fabric passes through the dyeing phase which, also, is carried out entirely by ten subcontractors. Eight of them are located in the outskirts of Athens ensuring fast response to the company's demands. The dyed fabric is inspected thoroughly for stains, holes, and colour homogeneity.

\section{Cutting}

This activity is considered by the company critical; therefore it is performed entirely in-house. Rarely, and only in the case of capacity constraints, some cutting can be done by the plant in Bulgaria. The actual cutting is being done by a Lectra $\mathrm{CAD} / \mathrm{CAM}$ machine. The cut items are pushed through another quality control which separates the cutting scrap from the ready to be assembled items.

\section{Assembly}

This activity is performed almost entirely by outsiders. $50 \%$ of the clothes are assembled by a force of 35 small-size subcontractors all over Greece, $40 \%$ by the plant and subcontractors in Bulgaria, and $10 \%$ by the two internal assembly lines which are also responsible for the correction of defective clothing (mending etc.). The assembled clothes, as soon as they return to the factory storage area, are pushed trough a $10 \%$ random quality inspection, which may expand first to a further $10 \%$, and end up to item-by-item inspection, if the inspected batch fails the first two controls.

\section{Finishing}

This phase is labour-intensive and does not require any particular machinery. It is split into three parts: Ironing, on line quality control of each single article, and packaging. Nearly $50 \%$ of this activity is performed in house with a cost similar or less than that of the existing active ten subcontractors. The end items, as soon as they return from the subcontractor, are inspected one by one, packaged again, and then follow their way to the end-product storage room, where they wait to be shipped to domestic or international customers. 


\section{LOGISTICS PLANNING MODEL}

The notion of the extended enterprise is well described in Browne/Sackett/ Wortmann (1995) and Jarillo (1993). The globalization and mass customisation pressures combine to force individual enterprises to work together across the value chain in order to meet customer needs. This results to inter-enterprise networking which is called extended enterprise. Approaches like JIT and Lean Production fit well into this context of the extended enterpise.

According to Jarillo (1993) the extended enterprise - which he calls strategic networks - should not be confused with a network of subcontractors. A strategic network should provide companies with the advantages of the two traditional organizational forms, i.e. vertical integration and subcontracting, without most of their drawbacks.

\section{GENERIC GRA GRID-HELEN'S CLUB S.A}

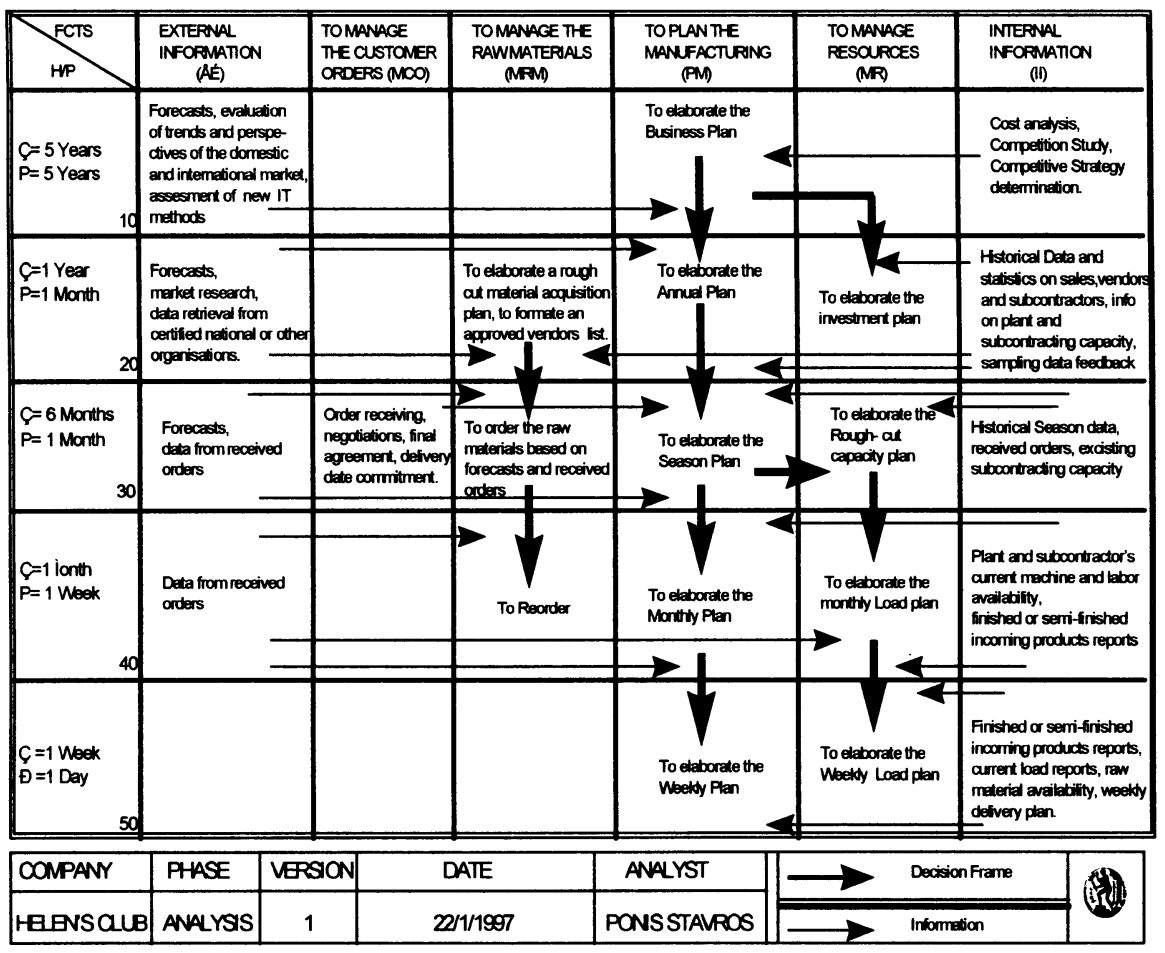

Figure 2 Helen's Club Global Decision Model.

Such a strategic network should be in a position to integrate its information systems and not just to rely on EDI solutions for exchanging data. In this case, the unification of bills of materials and routings, on the one hand, and of work centres 
and suppliers, on the other, may prove itself to be a powerful tool for managing resources and planning activites across the network. The characteristic of the extended enterprise is that the work previously done by a single industrial company is now split across a network of suppliers and cooperating partners (Figure 3 ). In this network, the nodes (suppliers) play the role of work centres and suppliers should have capacity attributes. Therefore, a planning system that treats work centres and suppliers in a uniform way seems only natural in this environment.

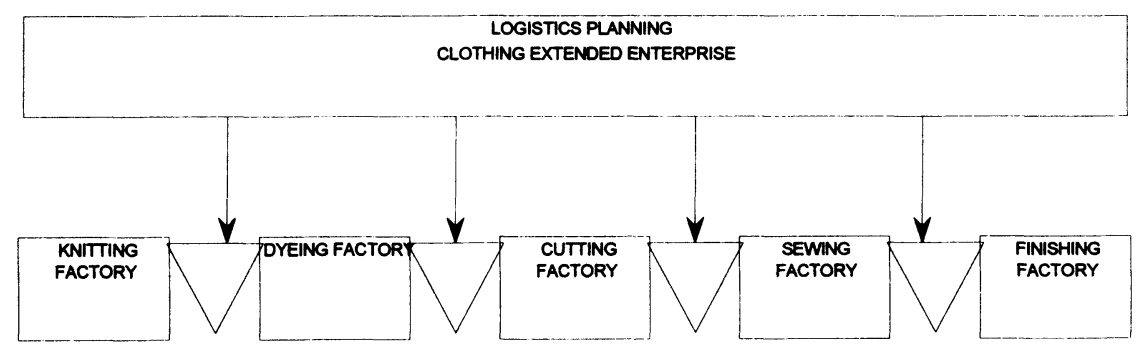

SUBCONTRACTORS

Figure 3 Overview of logistics planning in the clothing extended enterprise.

\subsection{Data Model}

The classical conceptual database schema for the basic state-independent data of production management systems (Scheer, 1988), includes data entities to define parts and their structures (bills of material), processing (routings, operations), capacities (work centres, machines, personnel) and suppliers.

The proposed data model, designed so as to be suitable for extended enterprises, introduces two new types of entities, viz a "Resources" entity which unifies bills of materials and routings and a "Sources" entity which unifies work centres and suppliers. These unifications make possible the common planning of internal production departments and subcontractors.

\section{The Resources and Sources Object Classes}

Both materials and work-centre operations may be considered as "Resources" needed in manufacturing goods.

From a conceptual database design viewpoint, as implemented in the present study, we can have a single "Resources" object class. This "Resources" entity related to the "Structures" entity (parent-son relationships) forms the product networks that include both materials and operations (Figure 4).

Another step towards integration is taken by replacing the separate "work centres" and "suppliers" entities by a single "sources" entity. From the point of view of the production planner of an extended enterprise, the work centres and the suppliers are 
nothing else but sources providing either manufactured parts or raw materials. The design of our production database follows the object-oriented approach in order to achieve a reduction of entities and attributes through the explicit representation of commonality. This is done by defining a classification structure of the "Resources" and "Sources" objects. Within a classification structure, inheritance makes it possible to share attributes.

In this respect, the attributes that pertain to all "Resources" or to all "Sources" are defined higher in the classification structure, and are extended by the specializations (materials and operations, work centres and suppliers). The proposed production database conceptual schema can be seen in Figure4 and access paths as follows:

RESOURCE (ResourceNo, Description, DateChanged, Cost...)

MATERIAL (ResourceNo, Issues, Receipts, OnHand, Allocations, ...)

OPERATION (ResourceNo, SourceNo, SetupTime, StandardTime, Yield, ...)

SOURCE (SourceNo, Description, Location, Responsible, DateChanged, Quality-

Rating, DeliveryRating, ...)

WORK CENTRE (SourceNo, Efficiency, NumberOfShifts,

NumberOfMachines,...)

SUPPLIER (SourceNo, PaymentTerms, AmountTotal, ...)

RESOURCE REFERENCE (ResourceNo, SourceNo, LeadTime, Cost, ...)

STRUCTURE (ResourceNo, ResourceNo, Quantity)

\section{Part numbers and coding conventions}

The traditional part numbering and coding conventions in PPC systems with separate bills of materials and routings are the following:

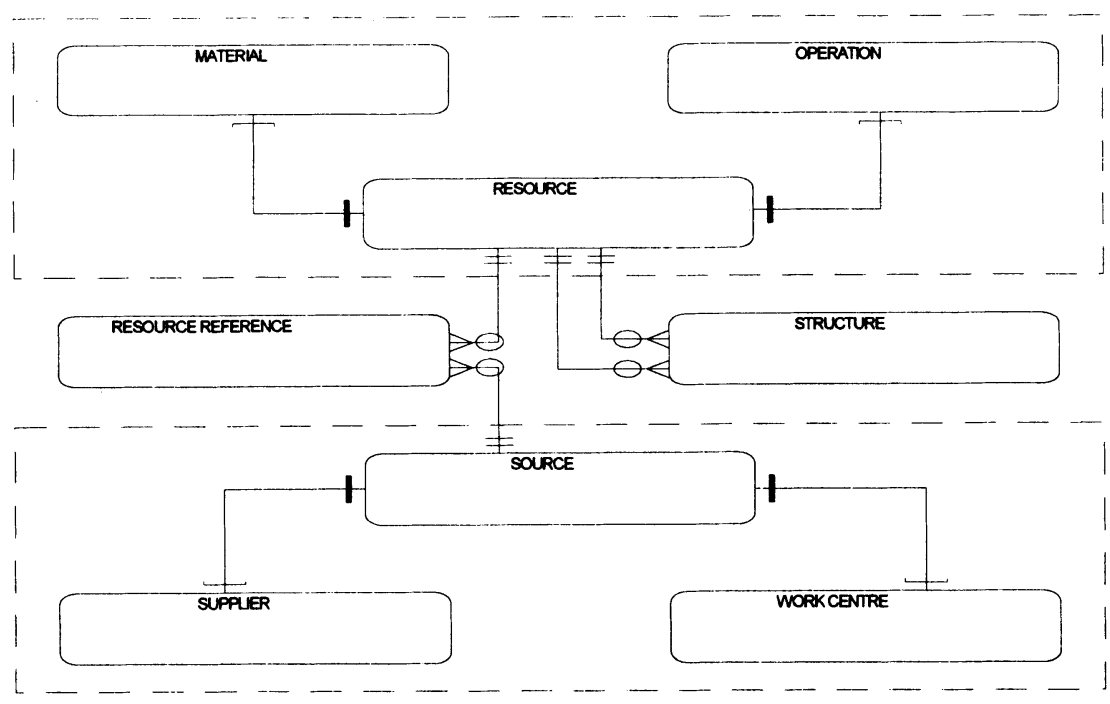

Figure 4 State-independent data model. 
1. A part number change is necessary at all points in the process where interface transactions may be anticipated and buffer stocks are required. To distinguish the items concerned, the part number should change just before the buffer stock, or store concerned. In other words,: you issue and you process a given name, but you deliver an object with a different name to the next buffer point, considering it to be the 'structural parent' of its predecessor. This is the origin of the genealogical terminology inherent in bill-of-materials and routing definitions.

2. A routing is the sequence of steps a part goes through from issue to delivery, i.e. it is the sub-process between name changes. The components in progress, whose aggregate constitutes the work-in-progress (WIP) inventory, are always expressed as 'child parts', whereas the routing always refers to the 'parent part', i.e. to the output of the sub-process.

The implications on the two main concepts of manufacturing management (bills of material and routings) are far-reaching and underline the importance of choices affecting part numbers.

When bills and materials are unified, a fundamental difference is induced in partnumber coding conventions, especially those concerning the intra-factory and the work-in-process inventory of extended enterprises. An important issue in production management systems is the way to store data that relate to inventory and work-inprocess inventory. Consider for example, the inventory of a particular part that has already been processed at a certain operation of the routing but has not yet been processed through the next operation. At this stage we have two ways to code this inventory. We can call it by the last operation it went through or, alternatively, we can arbitrarily assign it to the next operation it is supposed to be processed through. In traditional MRP systems, most of the work-in-process inventory is considered to be stored physically in the queue of the machine where it is to be further processed, therefore it is quite natural to assign the inventory to the next operation code.

When bills of materials and routings are unified, it is mandatory to always name inventory according to the last operation it went through. This data structure leads to the consolidation of both, the work-in-process and the stores inventory file.

\subsection{Function Model}

The unification of bills of materials and routings, as well as the unification of work centres and suppliers, have profound consequences on the structure of the logistics planning system. Those consequences lead to simultaneous material and capacity requirements planning and to comprehensive support of the extended enterprise.

\section{Simultaneous materials and capacity planning}

The above notion started as major critisism to the MRPII approach regarding the concept of successive material and capacity requirements planning. The results of the material requirements planning stage (MRP) are the input to the subsequent capacity 
requirements planning stage (CRP) so that feedback can be achieved only with difficulty. A further very strong drawback has its origin in the issue of planned lead times used in MRP calculations. The notion of MRP scheduling based on known average lead times makes MRP essentially capacity insensitive. It involves the major assumption that the actual shop floor loading at the time of planning conforms to these planned values, which is almost never the truth. What is needed is an integrated approach of simultaneous materials and capacity management (Scheer, 1989).

Another early effort is reported by Hastings et al. (1982) for an integrated approach to production scheduling and material requirements planning ("ScheduleBased MRP") that simultaneously computes a feasible production schedule and the related material requirements plan.

The unified network of bills of materials and routings and the modified coding conventions of part numbers and operations, helps to include the whole network of subcontractors as well as the local work centre stores in the standard MRP running. This modification has a number of significant and far-reaching results on the operation mode of the MRP system, namely:

A net-change MRP-like approach is used (Figure 5). In stage-by-stage MRP the Net Requirements of the parent item become Gross Requirements for its components. In the same way, when in our case we take the decision to change the production rate of a particular subcontractor or work centre, this change induces changes in the capacity requirements of the preceding subcontractor/work centre. What we need is a flow network showing the relations between the subcontractors/work centres in the extended enterprise in exactly the same way that the bills of material of the products are stored. This was initially the basic idea behind DRP (Distribution Requirements Planning), see Vollmann et al., 1988. However, DRP did not take into account the capacities of the nodes in the network ofsuppliers.

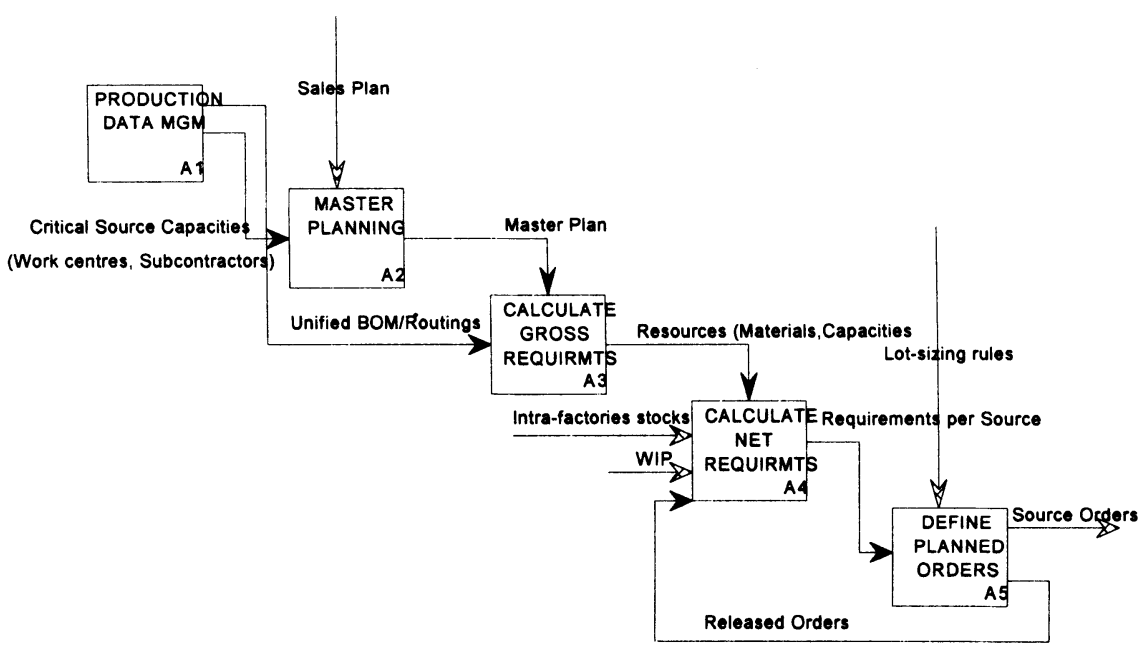

Figure 5 Function model of logistics planning. 
Important features of the proposed logistics planning system are:

- The average manufacturing lead times used by the MRP system for offsetting calculations refer now to sub-contractors' capacity rather than to supply-orders lead times. This makes them much more accurate.

- Intra-factory inventories are taken into account in the MRP.

- Work orders are issued directly to the sub-contractors' critical work centres instead of supply orders usually directed to the inventory system of the supplier.

- The MRP lot-sizing rules may be applied locally at the sub-contractor's critical capacities rather than the sub-contractor's warehouse as foreseen by standard MRP. This gives the opportunity to take advantage of local lot-sizing rules, which are imposed either by technological or by capacity-utilization factors (e.g. increased bottleneck capacity).

The implications regarding the data model covering the material and capacity requirements planning are presented in Figure 6 (approach of this study for simultaneous material and capacity planning).

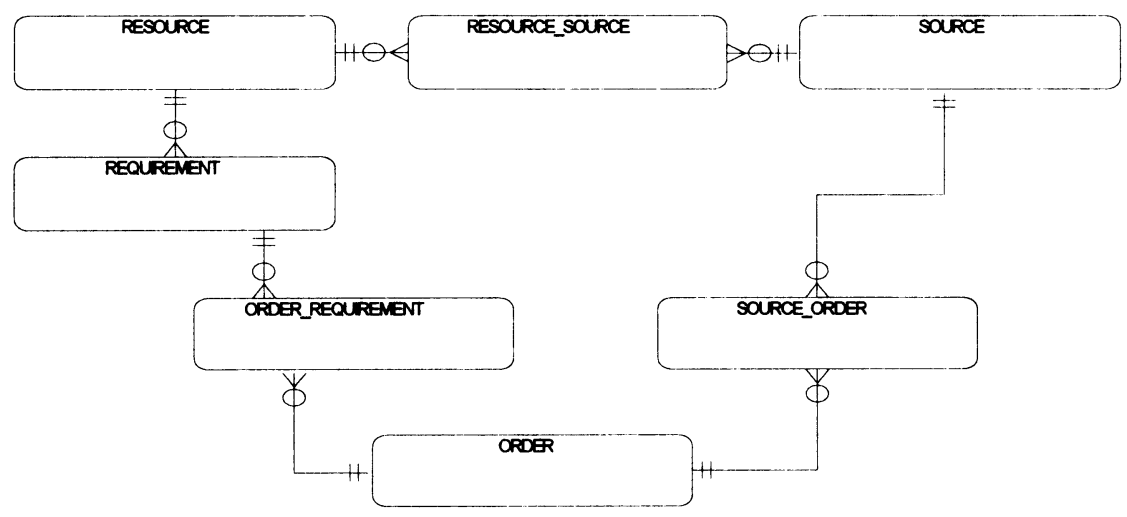

Figure 6 State-dependent data model

The clothing industry has traditionally used the "repetitive lot concept" (Vollmann et al., 1988) by separating the shop-order lots from the transfer lots (bundles). The above concept permits that the original shop-order quantities released for manufacturing can be split into smaller transfer lots (bundles) which can flow immediately to the next operation prior to the completion of the operation at its current work centre. The bundles are, in effect, small predetermined sub-batches, which are integral fractions of the original order quantity that provide a work centre with the flexibility to begin the production of an order earlier than its completion time at the previous 
work centre. The repetitive lot concept is significantly facilitated in the clothing industry by the fact that setup times are practically negligible between operations.

The Shop Floor Control (SFC) function in most clothing factories starts with the arrival of the Production Orders from the logistics department, which is responsible for long- and medium-term production planning. Thereafter, it starts within the factory a scheduling procedure which can be viewed as a top-down chain of order releases. In the clothing manufacturing environment, production orders are split into batches of shop orders (cutting orders and assembly orders). Shop orders are released to the production departments or main production lines. Then the transfer lots (or bundles) are released (dispatched) to the work groups within the departments or production lines (Figure 7). The detailed data model needed for Shop Floor Control (SFC) of the clothing factory is shown in Figure 8.

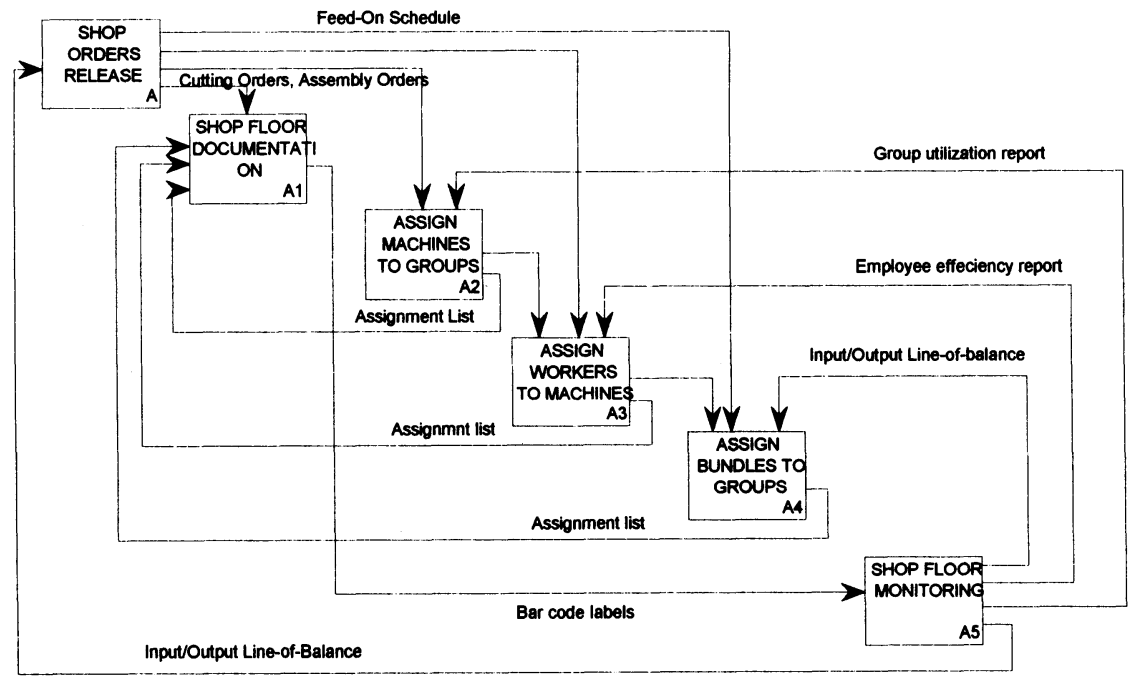

Figure 7 Clothing Factory Function Model.

The concept of discrete shop orders release (i.e. not time-phased) using the Input/Output Control (IOC) methodology (Plossl and Wight, 1973, Bechte, 1988, Wiendahl, 1987, Kingsman et al, 1989), is applied to this clothing industry as a twolevel hierarchical system:

1. At the Shop Orders release decision level

2. At the Bundle (production lot) assignment level

At the shop-order level the scheduling horizon covers 1-2 weeks. Whole work groups performing a sequence of operations are considered as black-box capacity units. A work group is defined as a group of different capacity units (sub-groups) 
connected by a line flow (e.g. production line, group technology cell). The role of the "job pool" is played by the unreleased shop orders file.

At the bundle level, the scheduling horizon covers one day or one shift. The purpose here is to control the flow within a work group using as capacity units the smaller sub-groups. A sub-group is defined as a group of identical worker skills doing parallel work. The role of the "job pool" is played by the bundle buffer.

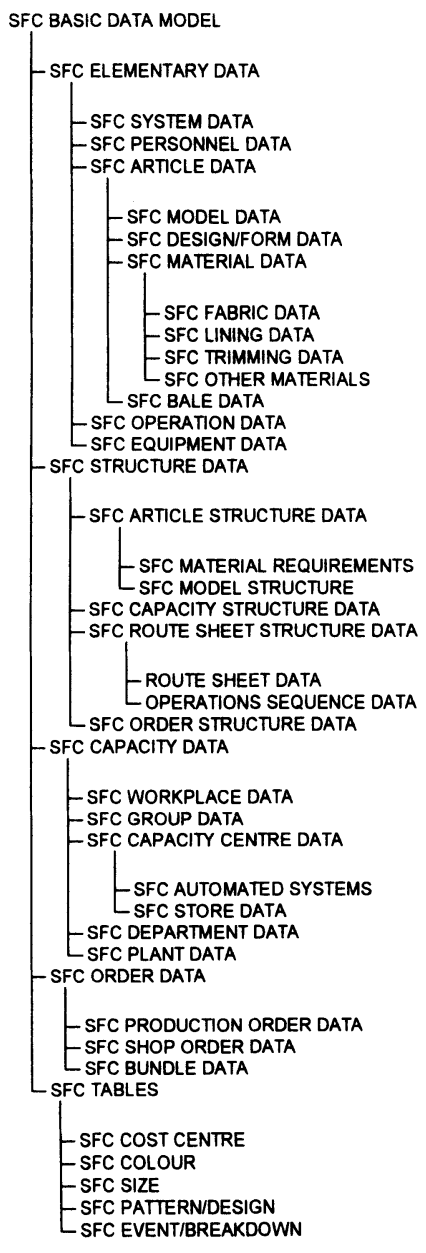

Figure 8 Clothing Factory Data Model Overview.

\subsection{Shop Orders Release}

Shop orders release takes place at successive weekly time periods and uses the "job pool" concept applied to the shop orders suspense file. That means that loading 
consists of the release into the shop of a subset of this file every week which is named "Feed-on Schedule". The releasing procedure is as follows:

1. Shop orders are allowed to remain unreleased for up to a maximum of a few time periods to form a backlog of unreleased orders (pool), with the maximum delay added to the manufacturing time to obtain the lead time.

2. Shop orders are released periodically in such a way that each work group and all its downstream groups are provided with a balanced inflow of work so that their mean released backlog lengths (actual queue plus released work residing in the upstream groups) do not exceed their maximum limits.

The loading algorithm attempts to control the released backlog lengths at all the work groups in order not to exceed their maximum norms and, at the same time, to take into account the shop-order priorities imposed by the promised delivery dates. The above problem at the higher DSS level of shop orders release is solved by a MIP (Mixed Integer Programming) quantitative model first developed by Irastorza (1974), which has been customized and formulated in this study for use in the clothing industry. The model has been implemented with the help of the SAS Institute's OR system (SAS, 1985).

\subsection{Work Group Control}

The operators in the production departments of clothing factories are allocated to groups. Each group has a product-oriented organization and performs a series of elementary operations, normally related to a part of the style (e.g. arm, collar). Each elementary operation is performed by sub-groups of similar operator skills. The significance of the operations-oriented group control is great due to the extremely labour intensive character of the industry. Apart from dispatching, the work group control module has also to take into account the purposes of shop documentation (bundles' bar coding), labour performance monitoring and payroll aspects related to bonus incentive schemes.

The release of bundles to the work groups takes place at the beginning of every day or shift under the constraints of the upper decision level of shop orders release. These constraints are expressed through the "Feed-on Schedule" document. The "job pool" concept is applied to the physical bundle buffer. The releasing procedure is as follows:

1. Bundles are allowed to remain in the physical buffer for up to a maximum of a few time periods.

2. Bundles are released periodically in such a way that each sub-group within the work group and all its downstream sub-groups are provided with a balanced inflow of work so that their mean released backlog lengths (actual queue plus released work residing in the upstream sub-groups) do not exceed their maximum limits. 
What we have here is a recursive application of input/output control (IOC) to the lower decision level where a different, refined definition is given to the terms work centre, job and job pool. The IOC problem at the work-group control decision level is solved by simple-priority rules-of-thumb and interactive trial methods. In this sense, it is data-oriented rather than model-based.

Another basic procedure of work group control is that, apart from selecting bundles from the buffer, which is an input control mechanism, an output control mechanism is applied as well through the reassignment of operators. This is a very short-term decision depending on factors like the availability of operators and their comparative skills.

\section{CONCLUSIONS AND FURTHER RESEARCH}

The business relationships between clothing companies and distributed factories with complementary skills and manufacturing abilities become much closer and more important if they adopt new logistics, communication, and management techniques which rely on computer-integrated logistics, EDI, and quick-response systems. As the delivery times between supplier and customer get shorter, the need for cooperation between dependent and independent clothing factories and their suppliers becomes more long-term in the form of the extended enterprise.

This research started by building a reference model of the logistics and production planning tasks in the clothing industry. The model needs further improvement to include all other types of clothing industries and be structured according to the CIMOSA structure of generic, partial and particular views.

Further directions of research are the product development and distribution processes of the clothing industry integrated to the production process. Today, the preparation of the production of new clothing styles and the communications needed, particularly the distribution of information, requires about $50 \%$ of the total throughput time. This period is too long for short-term reaction to customer demands and it is coupled with high-effort costs.

The sales and distribution process through a network of retail shops connected to multi-site factories needs futher study in the following areas: Multi-site and multifirm computerized logistics, Decision support for multi-site logistics, Integrated application of Electronic Data Interchange (EDI) for communication.

\section{7}

\section{LITERATURE}

Bechte, W. (1988) Theory and practice of load-oriented manufacturing control. Int. J. Prod. Res., Vol.26, No.3, 375-395.

Brite / Euram 2478 Project (1992) A Shop Floor Control System for the Clothing Industry. 
Browne, J., Sackett P.J. and Wortmann, J.C. (1996) Future Manufacturing Systems Towards the Extended Enterprise, Computers in Industry. Vol. 25, Nr. 3.

HELEN'S CLUB SA, NTUA (1996) Exrtended Network Enterprises in the Clothing Industry (Research funded by the Greek Ministry for Development).

Hastings, N.A. and Willis, R.J. (1982) Schedule Based MRP: An Integrated Approach to Production Scheduling and Material Requirements Planning, J. Opl. Res. Soc., Vol. 33, pp. 1021 to 1029.

ICI SA, NTUA, DYNASOFT SA (1994) Telematics Project, EDI in the Clothing Industry.

Irastorza, J.C. (1974) A Loading and Balancing Methodology for Job Shop Control, AIIE Transactions, Vol. 6, No. 4, pp. 302-307.

Kingsman, B.G., Tatsiopoulos, I.P., Hendry, L.C. (1989) A Structural Methodology for Managing Manufacturing Lead Times in Make-To-Order Companies, Europ.J.of Oper.Res., 40, 196-209.

Komninos, G. (1988) IOC-JSS, Job-shop simulation with input/ouput control, Diploma Thesis, Dept. of Mechanical Engineering, NTU Athens, 1988 (in Greek).

Jarillo, C.J. (1993) Strategic Networks, Butterworth-Heinemann.

Lintow, H. (1990) Realization and test of a prototype of a basic module of Computer Integrated Mnaufacturing (CIM) in the clothing industry, EEC BRITE Workshop, Paris, 6 November.

NIXDORF (1988) Entwicklung eines Informations- und kommunikationssystems der Rechnerintegrierten Fertigung in der Bekleidungsindustrie, EEC BRITE Project Gemeinsamer Endbericht (Berlin: Nixdorf Software Engineering).

Plossl, G., Wight, O. (1973) Capacity planning and control, Production and Inventory Management, 3rd Qtr., pp. 31-67.

SAS (1985) SAS-OR User's Guide Version 5.0 (North Carolina: SAS Institute). Scheer, A. (1988) CIM - Computer Steered Industry (Springer Verlag, Berlin)

Vollmann, Th., Berry,W., Whybark, D.C. (1988) Manufacturing Planning and Control Systems (Illinois: Irwin).

Wiendhal, H.P. (1987) Belastungsorientierte Fertigungssteuerung (München: Carl Hanser Verlag). 